\title{
An In-Silico Structural Characterization of the Buffalo Steroidogenic Proteins
}

\section{Emmagouni Sharath Kumar Goud, Mamta Pandey, Prashant Singh, Chhama Singh, Vedamurthy Gowdar Veerappa, Dheer Singh and Suneel Kumar Onteru*}

Molecular Endocrinology, Functional Genomics, and Systems Biology Lab, Animal Biochemistry Division, ICAR-National Dairy Research Institute, Karnal, India

*Corresponding Author: Suneel Kumar Onteru, Senior Scientist, Molecular Endocrinology, Functional Genomics, and Systems Biology Lab, Animal Biochemistry Division, ICAR-National Dairy Research Institute, Karnal, India.
Received: February 06, 2020

Published: February 21, 2020

(C) All rights are reserved by Suneel Kumar Onteru., et al.

DOI: $10.31080 /$ ASVS.2020.02.0051

\begin{abstract}
Post-partum reproductive disorders are of major concern in buffaloes. Mainly these are regulated by steroidogenic proteins, such as CYP17, CYP19, and 3 $\beta$-HSD. These enzymes are involved in the synthesis of several steroid hormones, an imbalance in the levels of which can lead to the causation of several reproductive illnesses ultimately affecting milk production. In the present in silico study, we analyzed the structural details of the three steroid enzymes in terms of their physiochemical properties, N- and 0-glycosylation sites, phosphorylation sites, secondary structure, surface probability, hydrophilicity and antigenic index. Additionally, the 3D models for the three proteins were enacted in the SWISS-MODEL online tool and the models were assessed by RAMPAGE. It was found that the CYP17 protein sequence of buffalo is small having 247 aminoacids when compared with other species. All the three buffalo steroid proteins were having more than $95 \%$ similarity with cattle, sheep and goat, except human. The amino acids responsible for the heme-binding site in CYP17, a catalytic site in CYP19, and 3 $\beta$-HSD proteins in buffalo were found to be conserved when compared with human protein sequences. The 3D models predicted for the three buffalo steroidogenic proteins were found to be of good quality through Ramachandran plot. Further, the individual phylogenetic trees for each of the protein showed that human proteins are phylogenetically outgroup to buffalo proteins. Overall, the in-silico analysis of the three buffalo steroidogenic proteins could prove to arise new insights for resolving reproductive disorders in the buffaloes.
\end{abstract}

Keywords: Steroidogenic; In-Silico; Buffalo; Steroid

\section{Introduction}

Buffaloes are one of the premier dairy animals in developing countries, especially in South East Asia. For example, India is one of the top countries in milk production with an annual production of 155.5 million tons in 2015-16 [1]. Buffaloes contribute about 55\% [2] of the total milk production in India. Although this contribution is prominent to the dairy sector, the milk productivity of buffaloes is not up to the mark. Reproductive problems are one of the reasons for less productivity in buffaloes.

Postpartum anestrus condition, polycystic ovaries, infertility etc., are the major reproduction problems in buffaloes. There can be many reasons for these reproductive problems, one of which is a hormonal imbalance. For instance, cystic ovaries consisting of persistent corpus leuteum produces high levels of progesterone which leads to anestrus condition. Polycystic ovary condition also leads to hyperandrogenism [3]. Considering the molecular insights, these problems may arise due to an improper expression of genes and proteins involved in hormone synthesis pathways. Three such proteins of major importance in steroid hormone, particularly estrogen biosynthesis, are cytochrome P450 17 alpha-hydroxylase/17,

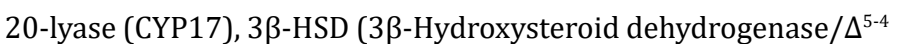
isomerase) and CYP19 (Cytochrome P-450 aromatase).

The CYP17and CYP19 are the members of cytochrome P450 superfamily of enzymes involved in steroid biosynthesis. These proteins are primarily localized in the endoplasmic reticulum (ER) membrane [4]. The CYP17 shows $17 \alpha$-hydroxylase and 17, 20-lyase activities. The $17 \alpha$-hydroxylase catalyzes the hydroxylation of pregnenolone and progesterone into $17 \alpha$-hydroxy pregnenolone and $17 \alpha$-hydroxy progesterone, respectively. The 17, 20-lyase activ- 
ity is involved in the conversion of $17 \alpha$-hydroxy pregnenolone and $17 \alpha$-hydroxy progesterone to dehydroepiandrosterone and androstenedione, respectively. It was found that mutations in the CYP17 gene leads to a deficiency of $17 \alpha$-hydroxylase/17, 20-lyase causing pseudo hermaphroditism, adrenal hyperplasia, amenorrhea and the lack of secondary sexual characteristics in women [5]. Amenorrhea or lack of female sexual cycles is a kind of similar condition of true anestrus in buffaloes. Hence, characterization of the CYP17 protein is important even in buffaloes.

Aromatase is the key enzyme for estrogen biosynthesis encoded by the CYP19 gene [6]. Aromatase catalyzes the conversion of androstenedione to estrone and testosterone to estradiol by aromatization at ring A. The catalytic complex of CYP19 includes the aromatase enzyme with a catalytic iron-binding porphyrin ring as a prosthetic group in the active site, and the NADPH-cytochrome P450 reductase enzyme having required amount of NADPH for the reaction [7]. The deficiency of aromatase enzyme results in the low levels of estrogens in the ovaries which could be a reason for silent heat in buffaloes. Silent heat may be a predominant cause of anestrus cases in the field conditions [8]. The lower activity of aromatase results in hyperandrogenism which may lead to anovulation and infertility [9]. However, aromatase protein and its structure is not yet well elucidated in buffaloes.

The $3 \beta$-HSD (3$\beta$-Hydroxysteroid dehydrogenase $/ \Delta^{5-4}$ isomerase) is the enzyme involved in the biosynthesis of progesterone from pregnenolone, $17 \alpha$-hydroxy progesterone from $17 \alpha$-hydroxy pregnenolone, androstenedione from DHEA in steroid hormone biosynthesis pathways. Its deficiency resulted in lower levels of estrogens, which necessitates the sex hormone therapy at puberty in humans [10]. As late maturity is one of the common problems in buffaloes, understanding the buffalo $3 \beta$-HSD at the molecular level is required.

The goal of this manuscript is to analyze the structural details of the three important proteins (CYP17, CYP19, and 3 $\beta$-HSD) of the steroidogenesis pathway in buffaloes. This preliminary step through computational biology may help to modulate these protein activities in the future for handling the reproductive problems of buffaloes.

\section{Materials and Methods}

Sequence retrieval and Multiple sequence alignment (MSA)

The amino acid sequences of the buffalo CYP17, CYP19,and3 $\beta$ HSD proteins were retrieved from the NCBI protein database. The retrieved buffalo protein sequences were used in the BLASTp online tool to get the protein sequences for other species like cow, goat, sheep, and human. The details of the protein sequences along with their species name, gene name and accession numbers are presented in table 1 . The sequences were retrieved in a fasta format and aligned through Clustal $\Omega$ online tool with default parameters [11].

\begin{tabular}{|l|c|c|c|}
\hline \multirow{2}{*}{$\begin{array}{l}\text { Species } \\
\text { Name }\end{array}$} & \multicolumn{3}{|c|}{ Protein IDs } \\
\cline { 2 - 4 } $\begin{array}{l}\text { Bubalus } \\
\text { bubalis }\end{array}$ & XP_006065001.1 & ABD64825.2 & XP_006049419.1 \\
\hline $\begin{array}{l}\text { Bos } \\
\text { taurus }\end{array}$ & NP_776729.1 & AAA62244.1 & NP_776768.1 \\
\hline $\begin{array}{l}\text { Bos } \\
\text { indicus }\end{array}$ & XP_019844145.1 & XP_019824386.1 & XP_019812272.1 \\
\hline $\begin{array}{l}\text { Ovis } \\
\text { aries }\end{array}$ & XP_011958253.1 & NP_001116472.1 & NP_001129404.1 \\
\hline $\begin{array}{l}\text { Capra } \\
\text { hircus }\end{array}$ & ABQ12616.1 & NP_001272676.1 & NP_001272645.1 \\
\hline $\begin{array}{l}\text { Homo } \\
\text { sapiens }\end{array}$ & AAA59984.1 & AAH35959.1 & NP_000853.1 \\
\hline
\end{tabular}

Table 1: Accession numbers of the steroidogenic proteins.

\section{Primary protein sequence analysis}

The physiochemical properties such as molecular weight, theoretical pI, amino acid composition, atomic composition, extinction coefficient, estimated half-life, instability index, aliphatic index and grand average of hydropathicity (GRAVY) were computed for the buffalo CYP17, CYP19, and 3 $\beta$-HSD protein sequences by online tool Protparam [12,13]. The N-Glycosylation, O-Glycosylation, and Phosphorylation sites of the these proteins were predicted using the online tools NetOGlyc 3.1 server [14,15], NetNGlyc 1.0 server $[16,17]$ and NetPhos 3.1 server [18,19], respectively. The signal peptide and transmembrane helices were predicted from the protein sequences using the SOSUI signal online software [20,21].

\section{Secondary and tertiary structure prediction}

The Protean tool (DNASTAR) was used for secondary structure prediction [22], hydrophilicity plot [23], antigenic index [24] and surface probability plot (Emini). The tertiary structure was predicted using the online software SWISS-MODEL $[25,26]$. The protein structure obtained from SWISS-MODEL was subjected to Ramachandran's plot analysis using the RAMPAGE online tool [27].

\section{Construction of phylogenetic tree}

The evolutionary tree was constructed by the MEGA7 software [28] using maximum likelihood method on the basis of Jones-Taylor-Thornton (JTT) matrix-based model [29]. For initial inference of the tree, the pairwise distances estimated by the JTT model between proteins were used for the heuristic search by applying the 
Nearest-Neighbour Interchange (NNI) and Bio NJ algorithms. The reliability of the branching of the tree was checked by 1000 bootstrap samplings [30]. The branches corresponding to the partitions were collapsed when they were reproduced in less than $50 \%$ of the bootstrap replicates. The gaps and missing data at all positions were eliminated.

\section{Ethical approval}

The present study is an in silico study utilizing the available online gene sequences and software. It does not involve any animal studies. Hence, the study does not require any animal ethics committee approval.

\section{Results}

Multiple sequence alignment

The MSA for the retrieved 247 amino acids (a.a) of buffalo CYP17 steroid protein showed $97.98 \%$ similarity with Bos taurus, 96.76\% with B. indicus, Ovis aries and Capra hircus, and $71.95 \%$ with that of Homo sapiens (Figure 1a). The buffalo CYP19 protein sequence showed approximately $98 \%$ similarity with all the above mentioned ruminant species and $83 \%$ with that of human (Figure 1b). Similarly, the buffalo $3 \beta$-HSD protein has $99 \%$ identity with $B$. taurus and B. indicus, 97\% identity with 0 . aries and $C$. hircus, and 79\% with H. sapiens sequence (Figure 1c).
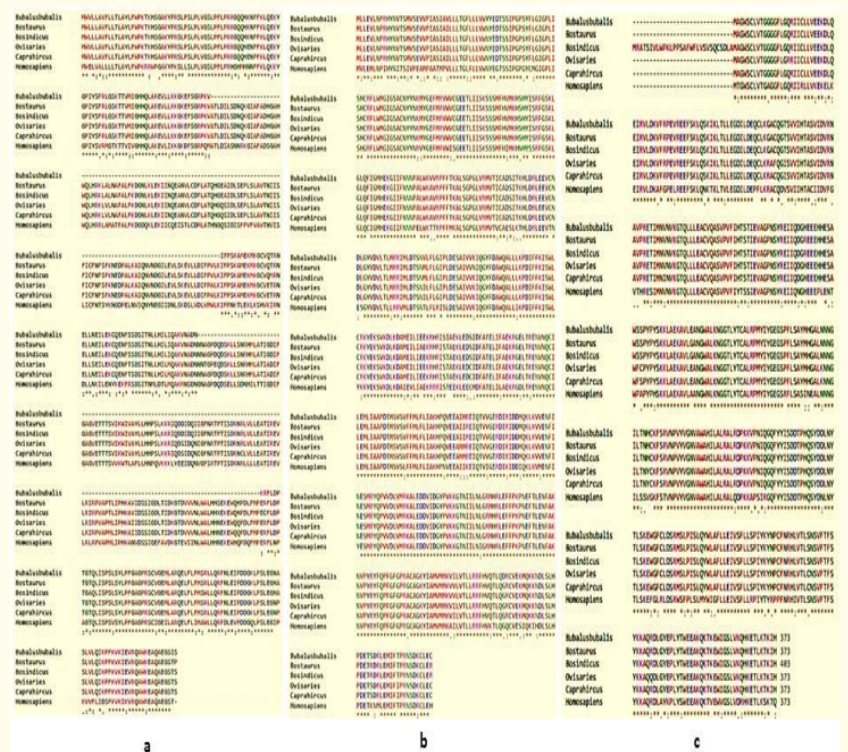

Figure 1

\section{Protein sequence analysis}

The number of negatively (Asp+Glu) and positively (Arg+Lys) charged amino acid residues were 20 and 11 for the CYP17, 61 and

\begin{tabular}{|c|c|c|c|c|}
\hline S. No & Properties & CYP17 & CYP19 & $3 \beta$-HSD \\
\hline 1. & No. of amino acids & 247 & 503 & 373 \\
\hline 2. & Molecular weight & 27999.9 & 58071.27 & 42272.55 \\
\hline 3. & Theoretical Pi & 9.86 & 6.87 & 7.17 \\
\hline \multirow[t]{21}{*}{4.} & $\begin{array}{c}\text { Amino acid composition } \\
(\%)\end{array}$ & & & \\
\hline & Ala (A) & 5.3 & 4.4 & 5.9 \\
\hline & $\operatorname{Arg}(\mathrm{R})$ & 5.3 & 5.6 & 3.8 \\
\hline & $\operatorname{Asn}(\mathrm{N})$ & 3.6 & 4.0 & 4.6 \\
\hline & Asp (D) & 2.0 & 5.2 & 3.5 \\
\hline & Cys (C) & 1.2 & 2.2 & 2.4 \\
\hline & $\mathrm{Gln}(\mathrm{Q})$ & 5.3 & 2.4 & 4.0 \\
\hline & Glu (E) & 6.1 & 7.0 & 7.0 \\
\hline & Gly (G) & 6.5 & 5.0 & 6.4 \\
\hline & His $(\mathrm{H})$ & 2.0 & 2.4 & 3.2 \\
\hline & Ile (I) & 4.9 & 8.0 & 5.9 \\
\hline & Leu (L) & 14.6 & 10.9 & 11.3 \\
\hline & Lys (K) & 8.9 & 6.4 & 6.7 \\
\hline & Met (M) & 2.4 & 5.0 & 1.3 \\
\hline & Phe (F) & 6.1 & 5.8 & 3.5 \\
\hline & Pro (P) & 6.5 & 4.2 & 4.3 \\
\hline & Ser $(S)$ & 8.1 & 5.8 & 7.2 \\
\hline & $\operatorname{Thr}(\mathrm{T})$ & 3.2 & 3.8 & 5.1 \\
\hline & $\operatorname{Trp}(\mathrm{W})$ & 1.2 & 1.2 & 2.1 \\
\hline & $\operatorname{Tyr}(\mathrm{Y})$ & 2.0 & 3.2 & 4.8 \\
\hline & Val (V) & 4.9 & 8.0 & 7.0 \\
\hline 5. & $\begin{array}{c}\text { Total number of } \\
\text { negatively charged } \\
\text { residues (Asp + Glu) }\end{array}$ & 20 & 61 & 39 \\
\hline 6. & $\begin{array}{c}\text { Total number of } \\
\text { positively charged } \\
\text { residues (Arg + Lys) }\end{array}$ & 35 & 60 & 39 \\
\hline \multirow[t]{6}{*}{7.} & Atomic composition: & & & \\
\hline & Carbon (C) & 1279 & 2634 & 1915 \\
\hline & Hydrogen $(\mathrm{H})$ & 2041 & 4157 & 2972 \\
\hline & Nitrogen $(\mathrm{N})$ & 343 & 681 & 504 \\
\hline & Oxygen $(0)$ & 343 & 722 & 548 \\
\hline & Sulfur (S) & 9 & 36 & 14 \\
\hline 8. & Formula & $\begin{array}{l}\mathrm{C}_{1279} \mathrm{H}_{2041} \\
\mathrm{~N}_{343} \mathrm{O}_{343} \mathrm{~S}_{9}\end{array}$ & \begin{tabular}{|c|}
$\mathrm{C}_{2634} \mathrm{H}_{4157}$ \\
$\mathrm{~N}_{681} \mathrm{O}_{722} \mathrm{~S}_{36}$ \\
\end{tabular} & $\begin{array}{l}\mathrm{C}_{1915} \mathrm{H}_{2972} \\
\mathrm{~N}_{504} \mathrm{O}_{548} \mathrm{~S}_{14}\end{array}$ \\
\hline 9. & Total number of atoms & 4015 & 8230 & 5953 \\
\hline 10. & $\begin{array}{l}\text { Extinction coefficients } \\
\left(\mathrm{M}^{-1} \mathrm{~cm}^{-1} \text {, at } 280 \mathrm{~nm}\right)\end{array}$ & 24075 & 57465 & 71320 \\
\hline 11. & Estimated half-life & & & \\
\hline (a) & $\begin{array}{l}\text { Mammalian reticulo- } \\
\text { cytes, in vitro }\end{array}$ & 30 hours & 30 hours & 30 hours \\
\hline
\end{tabular}




\begin{tabular}{|c|c|c|c|c|}
\hline (b) & Yeast, in vivo & $>20$ hours & $>20$ hours & $>20$ hours \\
\hline (c) & Escherichia coli, in vivo & $\begin{array}{c}>10 \\
\text { hours }\end{array}$ & $\begin{array}{c}>10 \\
\text { hours }\end{array}$ & $\begin{array}{c}>10 \\
\text { hours }\end{array}$ \\
\hline 12. & Instability index (II) & 41.39 & 32.42 & 43.57 \\
\hline 13. & Aliphatic index & 95.14 & 101.09 & 93.03 \\
\hline 14. & $\begin{array}{c}\text { Grand average of hy- } \\
\text { dropathicity (GRAVY) }\end{array}$ & -0.181 & 0.063 & -0.194 \\
\hline
\end{tabular}

Table 2: In-silico analysis for the physicochemical properties of buffalo steroid biosynthesis proteins.

60 for the CYP19 and 39 and 39 for the $3 \beta$-HSD. The total number of negatively charged residues (Asp+Glu) and positively charged residues (Arg+Lys) were known to indicate the nature of proteins. Accordingly, the CYP17 is basic in nature with an overall positive charge, and the CYP19 and 3 $\beta$-HSD proteins are neutral in nature. The other properties like molecular weight, theoretical pI, amino acid composition, atomic composition, extinction coefficient, estimated half-life, instability index, aliphatic index, grand average of hydropathicity (GRAVY) etc., were also computed as shown in table 2. The instability index (32.42), aliphatic index (101.09) and GRAVY score (0.063) indicated that buffalo CYP19 had higher stability in a test tube (in vitro), thermostability and hydrophobicity than the CYP17 and $3 \beta$-HSD.

The analysis of O-glycosylation, N-glycosylation, and Phosphorylation sites revealed the absence of significant O-glycosylation sites in all the three proteins. However, the CYP17, CYP19, and 3 $\beta$-HSD have only one N-glycosylation site at Asn217, Asn12, and Asn268, respectively. Similarly, the CYP17, CYP19, and 3 $\beta$-HSD have 14,33 and 34 phosphorylation sites, respectively.

By using the SOSUI signal software, we predicted that CYP17 protein consisted of one signal peptide but lacks transmembrane helices, the CYP19 consisted of one transmembrane helix but lacks a signal peptide, and the $3 \beta$-HSD consisted of both signal peptide and transmembrane helix. The signal peptide of CYP17 is of 17 a.a. in length present at the $\mathrm{N}$-terminal end starting from the $1 \mathrm{st}-17^{\text {th }}$ position. The transmembrane helix of the CYP19 protein was found to be of 23 a.a length present at the $\mathrm{N}$-terminal end starting from $17^{\text {th }}-39^{\text {th }}$ position. The signal peptide and transmembrane helix of $3 \beta$-HSD were of 25 a.a's from $1^{\text {st }}-25^{\text {th }}$ position and 23 a.a's length from the $289^{\text {th }}-311^{\text {th }}$ position, respectively.

\section{Secondary and tertiary structure prediction}

Upon comparative secondary structure analysis, it was observed thatCYP19 protein has more alpha helices and beta sheets than CYP17 and3 $\beta$-HSD protein sequences, whereas the turns are more in number in CYP17 and coils are more in CYP17 and 3 $\beta$-HSD than CYP19. The antigenicity was found to be higher for CYP19 followed by $3 \beta$-HSD and CYP17 on the basis of a number of antigenic peptides (Figure 2).

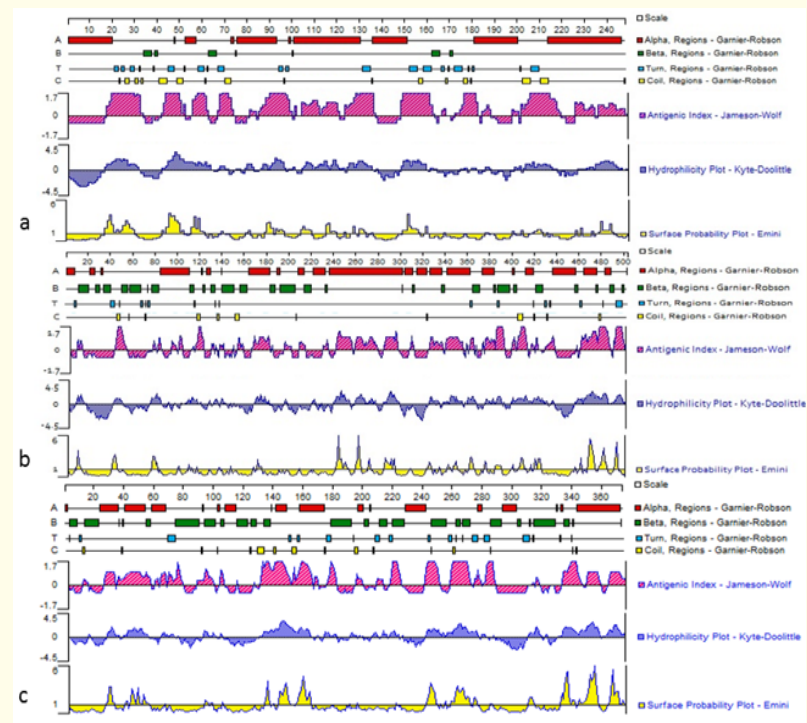

Figure 2

The tertiary structures of the three buffalo steroid proteins were predicted through the SWISS-MODEL (Figure 3). The tertiary structures thus obtained were submitted to RAMPAGE in PDB format for the validation of predicted protein structures. From the Ramachandran plot, it was analyzed that CYP17 protein has $96.2 \%$ of residues in the favored region, $2.4 \%$ in the allowed region and $1.4 \%$ in the outlier region. The CYP19 protein has $94 \%$ in the favored region, $5.8 \%$ in the allowed region and $0.2 \%$ in the outlier region. The $3 \beta$-HSD protein had $89.3 \%$ in the favored region, $8.6 \%$ in the allowed region and $2.1 \%$ in the outlier region (Figure 4 ).
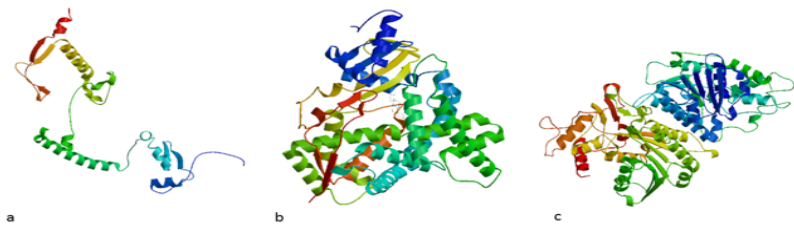

Figure 3

\section{Construction of phylogenetic tree}

The phylogenetic tree constructed using MEGA7 software depicted that the CYP17 protein of Bubalus was phylogenetically more similar to both Bos taurus and Bos indicus proteins than 


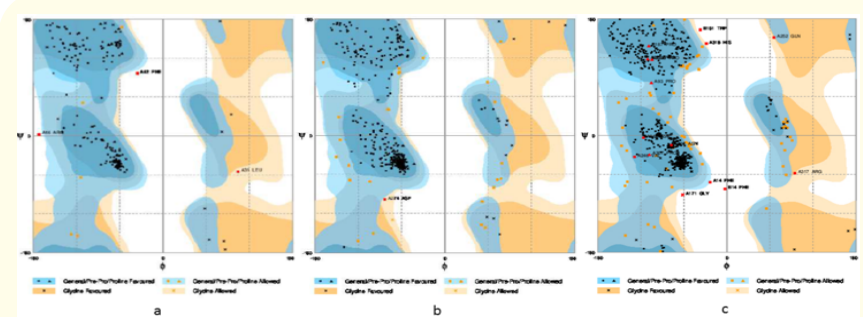

Figure 4

other species sequences. CYP19 protein of buffalo was more phylogenetically similar to small ruminant species i.e. Ovis and Capra than large ruminants and human sequences. However, the buffalo $3 \beta$-HSD and CYP17 proteins were found to be more similar to Bos taurus and Bos indicus than small ruminants and humans (Figure 5).

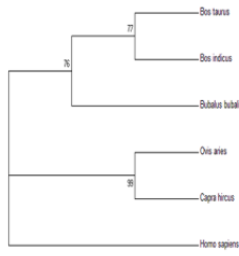

a

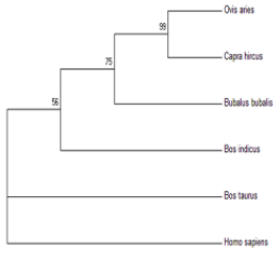

b

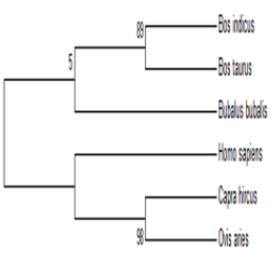

c
Figure 5

\section{Conclusion}

The present study provides the in-silico analysis and structural models of the three buffalo proteins which are involved in steroidogenesis i.e. CYP17, CYP19, and 3 $\beta$-HSD. These proteins play a crucial role in the metabolism of cholesterol towards the synthesis of various steroid hormones, especially of those involved in reproduction [31]. Considering the importance of these three enzymes or proteins in steroidogenesis, and their structural details are unknown for buffaloes, it becomes necessary to know their properties and structure for buffaloes. A single defect in any of these three proteins could affect the reproductive cycle of buffaloes, leading to a decrease in their reproductive efficiency, thus productivity.

The CYP17 buffalo protein sequence, as predicted by NCBI, is smaller (247 a.a) than the protein sequences of other species, which are of nearly 500 a.a. The heme-binding site of CYP17 was found at 171-191 position in buffalo protein sequence. This sequence of heme binding site is present at a $433-453$ position in the human CYP17 protein sequence [32]. Sequence alignment of buffalo and human CYP17 proteins inferred that the conserved positively charged arginine residue having selective lyase activity is present at the 187 th position in buffalo sequence instead of $449^{\text {th }}$ position [33] of the human and other species sequence.

The amino acid number for the CYP19 was observed to be the same for all the species (503 a.a) used for comparison in this study. The amino acid residues present at positions i.e. F134, F221, W224, I305, A306, D309, T310, V370, L372, V373, M374, L477, and S478 were contributing to the catalytic cleft of human aromatase [34] where androstenedione precisely fits in the cleft. Upon comparison of the residues, we can state that the catalytic cleft residues of the buffalo and human aromatase are exactly same and conserved for a CYP19 protein sequence. Hence, it may be possible to use inhibitors (e.g., letrazol) or activators (e.g.., zeranol) of human aromatase to modulate the activity of buffalo aromatase. Future in vitro and in vivo studies are required to understand the effect of human aromatase inhibitors in buffaloes to mitigate the reproductive problems.

In the present study, buffalo $3 \beta$-HSD protein sequence was found to be $79 \%$ similar to human $3 \beta$-HSD protein sequence. This finding was in accordance with the reports of Zhao., et al. [35], who also observed a similar identity for bovine and human $3 \beta$-HSD protein sequence. $3 \beta$-HSD protein is of two types i.e. type $13 \beta-H S D$ and type $23 \beta$-HSD. The difference is for the presence of the type of amino acid at the $187^{\text {th }}$ amino acid residue which is methionine for type $13 \beta$-HSD and threonine for type $23 \beta$-HSD [36]. By analyzing the amino acid composition of the buffalo $3 \beta$-HSD protein in the present work, it can be inferred that buffalo $3 \beta$-HSD protein sequence is of type $13 \beta-\mathrm{HSD}$ as methionine is present at a $187^{\text {th }}$ position in the sequence. In buffalo $3 \beta$-HSD, we found Glu142 and Tyr253 residues, which are believed to have a crucial role in its catalytic activity [37]. Also, Glu142 and Tyr253 are highly conserved in many species as well as in both $3 \beta$-HSD isoforms [37]. The key residues, Asn 100 and Glu126, were also conserved in buffalo $3 \beta$-HSD proteins. The Asn 100 and Glu126in human 3 $\beta$-HSD1 are involved in the dehydrogenase and isomerase activity, respectively [38].

The protein CYP17 and CYP19 are localized in the endoplasmic reticulum where the $\mathrm{pH}$ is 7.2 . The theoretical $\mathrm{pI}$ for the CYP17 is 9.86 and it has a number of positively charged amino acids, indicating its activity in the basic environment. Similarly, the theoretical pI of $3 \beta$-HSD was found to be 7.17 , signifying the stability of this protein in a basic environment. $3 \beta$-HSD is known to be localized in microsomes and mitochondria where $\mathrm{pH}$ is 8.0. The CYP19 having a theoretical pI of 6.87 showed its near stable subcellular localization in the ER. An instability index greater than 40 is an indication 
of instability of the protein in a test tube environment [39]. Considering the same, the buffalo CYP17 and 3 $\beta$-HSD are unstable while CYP19 is stable in a test tube system.

$\mathrm{N}$-linked glycosylations are universal modifications present in all eukaryotes [40] that can modify thermodynamic, kinetic and structural properties of the proteins depending on their sequence [41]. The prediction of N-glycosylation sites in buffalo CYP19 protein showed glycosylation at Asn12. The N-glycosylation at this specific site helps in subcellular localization of CYP19 protein into the lumen of ER (Kaur and Bose 2014). Similar to our study in the buffalo, the Asn12 site is also present in human aromatase [42]. In our study, $\mathrm{N}$-glycosylation site (Asn-X-Thr) was located at amino acids $268^{\text {th }}-270^{\text {th }}$ positions of $3 \beta$-HSD protein in Buffalo. This finding was similar to the reports of $3 \beta$-HSD protein in bovine [35], indicating its conserved function between buffaloes and cows.

In the present study, we noticed the absence of signal peptide in buffalo aromatase protein similar to human aromatase. Although the signal peptide is absent, the human aromatase protein was found to be translocated by signal anchor-mediated translocation [43]. A similar translocation mechanism may be expected for buffalo aromatase protein. In our study, the antigenic index, hydrophilicity, and surface probability were observed to have a correlated pattern for all the three steroidogenic proteins. The regions showing hydrophilic domains in the hydrophilicity plot showed higher antigenic index for all the three proteins. It was concluded that the regions with higher hydrophilicity and surface probability show higher antigenic index.

The results as obtained from Ramachandran plot had indicated that the maximum amino acid residues for all the three protein sequences were found to be present in the favored and allowed region indicating an overall stable protein configuration of the predicted structures. From the phylogenetic trees, we found that all the three proteins are well conserved in buffalo throughout the course of evolution.

\section{Conclusion}

In this study, the structural details of buffalo steroidogenic enzymes were characterized by in silico approaches. Particularly, physicochemical properties, glycosylation sites, phosphorylation sites, signal peptide, transmembrane helices, secondary and tertiary structure, antigenic index and a phylogenetic tree were identified for the three steroidogenic proteins. In the future, these structural details will be useful for designing drugs to target these proteins for therapeutics of buffalo reproductive disorders.

\section{Conflict of Interest}

The authors declare that they do not have any conflict of interests.

\section{Bibliography}

1. http://www.nddb.org/information/stats/milkprodindiaz

2. http://www.milkproduction.com/Library/Editorial-articles/ Milk-quality-in-India/

3. Puurunen J., et al. "Adrenal androgen production capacity remains high up to menopause in women with polycystic ovary syndrome". The Journal of Clinical Endocrinology and Metabolism 94.6 (2009): 1973-1978.

4. Neve EP and Ingelman-Sundberg M. "Cytochrome P450 proteins: retention and distribution from the endoplasmic reticulum". Current Opinion in Drug Discovery and Development 13.1 (2010): 78-85.

5. Fernández-Cancio M., et al. "Discordant genotypic sex and phenotype variations in two Spanish siblings with $17 \alpha$-hydroxylase/17, 20-lyase deficiency carrying the most prevalent mutated CYP17A1 alleles of Brazilian patients". Sexual Development 11.2 (2017): 70-77.

6. Kumar OS., et al. "CYP19 (cytochrome P450 aromatase) gene polymorphism in murrah buffalo heifers of different fertility performance". Research in Veterinary Science 86.3 (2009): 427-437.

7. Poulos TL., et al. "The 2.6-A crystal structure of Pseudomonas putida cytochrome P-450". Journal of Biological Chemistry 260.30 (1985): 16122-16130.

8. Hafez ESE and Hafez B. "Reproduction in farm animals". Lippincott Williams and Wilkins publications, (7ed) (2000): 261263.

9. Chen J., et al. "The correlation of aromatase activity and obesity in women with or without polycystic ovary syndrome". Journal of Ovarian Research 8.1 (2015): 11.

10. Kolon TF, et al. "Disorders of sexual development". Penn Clinical Manual of Urology, Elsevier Health Sciences (2007): 827852.

11. Sievers F., et al. "Fast, scalable generation of high-quality protein multiple sequence alignments using Clustal Omega". Molecular Systems Biology 7.1 (2011): 539. 
12. http://web.expasy.org/protparam/

13. Gasteiger, E., et al. "Protein identification and analysis tools on the ExPASy server”. Humana Press (2005): 571-607.

14. http://www.cbs.dtu.dk/services/NetOGlyc-3.1/

15. Julenius K., et al. "Prediction, conservation analysis, and structural characterization of mammalian mucin-type 0-glycosylation sites". Glycobiology 15.2 (2005): 153-164.

16. http://www.cbs.dtu.dk/services/NetNGlyc/

17. Gupta R., et al. "Prediction of N-glycosylation sites in human proteins". 46 (2004): 203-206.

18. http://www.cbs.dtu.dk/services/NetPhos/

19. Blom, N., et al. "Prediction of post-translational glycosylation and phosphorylation of proteins from the amino acid sequence". Proteomics 4.6 (2004): 1633-1649.

20. http://harrier.nagahama-i-bio.ac.jp/sosui/sosuisignal/sosuisignal_submit.html

21. Gomi M., et al. "High performance system for signal peptide prediction: SOSUI signal”. Journal of chem-bio informatics 4.4 (2004): 142-147.

22. Garnier J., et al. "GOR method for predicting protein secondary structure from amino acid sequence". Methods in Enzymology 266.32 (1996): 540-553.

23. Kyte J and Doolittle RF. "A simple method for displaying the hydropathic character of a protein". Journal of Molecular Biology 157.1 (1982): 105-132.

24. Jameson BA and Wolf H. "The antigenic index: a novel algorithm for predicting antigenic determinants". Bioinformatics 4.1 (1988): 181-186.

25. https://swissmodel.expasy.org/

26. Guex N., et al. "Automated comparative protein structure modeling with SWISS-MODEL and Swiss-PdbViewer: A historical perspective". Electrophoresis 30.S1 (2009).

27. http://mordred.bioc.cam.ac.uk/ rapper/rampage.php

28. Kumar S., et al. "MEGA7: Molecular Evolutionary Genetics Analysis version 7.0 for bigger datasets". Molecular Biology and Evolution 33.7 (2016): 1870-1874.
29. Jones DT., et al. "The rapid generation of mutation data matrices from protein sequences”. Bioinformatics 8.3 (1992): 275282.

30. Felsenstein J. "Confidence limits on phylogenies: an approach using the bootstrap". Evolution 39.4 (1985): 783-791.

31. Hu J., et al. "Cellular cholesterol delivery, intracellular processing and utilization for biosynthesis of steroid hormones". $\mathrm{Nu}$ trition and metabolism 7.1 (2010): 47.

32. Picado-Leonard., et al. "Cloning and sequence of the human gene for P450cl7 (steroid) 17 $\alpha$-hydroxylase/17, 20 lyase: similarity with the gene for P450c21". Dna 6.5 (1987): 439-448.

33. Akhatar MK., et al. "Cytochrome b5 modulation of $17 \alpha$ hydroxylase and 17-20 lyase (CYP17) activities in steroidogenesis". Journal of Endocrinology 187 (2005): 267-274.

34. Ghosh D., et al. "X-ray structure of human aromatase reveals an androgen-specific active site". The Journal of Steroid Biochemistry and Molecular Biology 118.4-5 (2010): 197-202.

35. Zhao HF., et al. "Molecular cloning, cDNA structure and predicted amino acid sequence of bovine $3 \beta$-hydroxy-5-ene steroid dehydrogenase/ $\Delta 5-\Delta 4$ isomerase". FEBS letters 259.1 (1989): 153-157.

36. Cravioto MDC., et al. "A new inherited variant of the $3 \beta$-hydroxysteroid dehydrogenase-isomerase deficiency syndrome: evidence for the existence of two isoenzymes". The Journal of Clinical Endocrinology and Metabolism 63.2 (1986): 360-367.

37. Simard J., et al. "Molecular basis of congenital adrenal hyperplasia due to 3 beta-hydroxysteroid dehydrogenase deficiency". Molecular Endocrinology 7.5 (1993): 716-728.

38. Pletnev VZ., et al. "Rational Proteomics V: Structure-based mutagenesis has revealed key residues responsible for substrate recognition and catalysis by the dehydrogenase and isomerase activities in human $3 \beta$-hydroxysteroid dehydrogenase/ isomerase type 1". The Journal of Steroid Biochemistry and Molecular Biology 101.1 (2006): 50-60.

39. Guruprasad K., et al. “Correlation between stability of a protein and its dipeptide composition: a novel approach for predicting in vivo stability of a protein from its primary sequence". Protein Engineering, Design, and Selection 4.2 (1990): 155-161. 
40. Weerapana E and Imperiali B. "Asparagine-linked protein glycosylation: from eukaryotic to prokaryotic systems". Glycobiology 16.6 (2006): 91R-101R.

41. Mitra N., et al. "N-linked oligosaccharides as outfitters for glycoprotein folding, form and function". Trends in Biochemical Sciences 31.3 (2006): 156-163.

42. Shimozawa 0., et al. "Core glycosylation of cytochrome P-450 (arom) Evidence for localization of $\mathrm{N}$ terminus of microsomal cytochrome P-450 in the lumen". Journal of Biological Chemistry 268.28 (1993): 21399-21402.

43. Kaur J and Bose HS. "Passenger Protein Determines Translocation Versus Retention in the Endoplasmic Reticulum for Aromatase Expression". Molecular Pharmacology 85.2 (2014): 290-300.

\section{Assets from publication with us}

- Prompt Acknowledgement after receiving the article

- Thorough Double blinded peer review

- Rapid Publication

- Issue of Publication Certificate

- High visibility of your Published work

Website: www.actascientific.com/

Submit Article: www.actascientific.com/submission.php

Email us: editor@actascientific.com

Contact us: +919182824667 